\title{
DIAGNÓSTICO DA GERAÇÃO DE RESÍDUOS DE CONSTRUÇÃO CIVIL: UM ESTUDO DE CASO DE CANTEIROS NA CIDADE DE PAU DOS FERROS/RN
}

\author{
Diagnosis of the generation of construction waste: a case study in the city of Pau dos Ferros/RN
}

\author{
Helcio Barros Barbosa, Adla Kellen D. S. de Oliveira, \\ Leonardo Henrique Borges de Oliveira
}

1 Universidade Federal Rural do Semi-Árido (UFERSA) - Campus Pau dos Ferros

\begin{abstract}
Resumo
Este trabalho trata-se de um diagnóstico da geração de resíduos da construção civil (RCC) nos canteiros de obra da cidade de Pau dos Ferros/RN. Para isso, foram realizadas visitas in loco, aplicação de questionário, registro fotográfico, caracterização visual do RCC e estimativa do volume de RCC presente na obra. Foi observado que a maior porcentagem de RCC é oriunda de construção, demolição e reforma. Da análise do questionário foi verificado que a etapa que mais contribui para a geração do resíduo é a de execução de revestimento. O volume de resíduo de construção civil verificado no momento da visita foi calculado e resultou em aproximadamente $180 \mathrm{~m}^{2}$. A partir do questionário, verificou-se que as obras geram resíduos que podem ser reutilizados ou reciclados, no entanto apenas uma obra visitada reutilizou os resíduos. Foi verificado que os responsáveis pelas obras desconhecem o destino final dos resíduos e a maioria não tem conhecimento sobre a reutilização ou reciclagem do resíduo. Com as informações obtidas durante a pesquisa, observa-se que há necessidade de adoção de políticas públicas com o objetivo de melhorar a gestão de resíduos de construção civil do município.
\end{abstract}

Palavras-chave: Impacto ambiental, Construção Civil, Resíduos de construção civil.

Abstract

This paper it is a diagnosis of generation construction waste at construction sites in the city of Pau dos Ferros / RN. Site visits, questionnaire application, photographic record, visual characterization of the waste and estimate of the waste construction volume were made in the developing of this work. It was observed that the highest percentage of waste is coming from construction, demolition and construction improvements. By the questionnaire analysis it was found that the step that contributes most to the waste generation is the coating. The volume of construction waste verified at the time of the visit, was calculated and resulted in approximately $180 \mathrm{~m}^{2}$. From the questionnaire, it was found that the works generate waste can be reused or recycled, however, only one visited site use the reused waste. It was found that those responsible for works doesn't know about the final destination of waste and most have no knowledge about the reuse or recycling of waste. With the information obtained during this research, it is observed that there is a need to adopt public policies aimed at improving the management of construction waste in the municipality.

Keywords: Environmental impact, Construction, Construction Waste. 


\section{Introdução}

Na vida moderna, todos os setores da economia dependem de um fluxo constante de materiais, em um ciclo que começa na extração de matérias-primas naturais, e segue em sucessivas etapas de transformações industriais, transporte, montagem, manutenção e desmontagem final (NATIONAL RESEARCH COUNCIL, 2004).

A construção civil é uma das atividades mais importantes para o desenvolvimento socioeconômico. Para Barbisan et al. (2012), apesar dessa importância, esse setor gera impactos avaliáveis ao meio ambiente. Esses impactos foram evidenciados com o rápido crescimento das cidades de grande porte e principalmente das cidades de médio porte quem têm acarretado um processo de urbanização acelerada.

O intenso processo de urbanização revela a quantidade de resíduos originados pelas obras, seja por demolições de edificações antigas ou por construções de edificações mais modernas. Porém, o processo de renovação urbana causa impacto ao meio ambiente por não haver uma busca por soluções mais adequadas. As municipalidades brasileiras de médio e grande porte não estão estruturadas para o gerenciamento de volume tão expressivo de resíduos e não podem mais postergar solução para os problemas acarretados por eles, continuando a agir de forma coadjuvante e emergencial, ao sabor da reação dos agentes geradores e coletores à ausência de soluções preventivas (PINTO, 1999). De acordo com Bernardes et al. (2008), para que ocorra um bom gerenciamento dos RCC é necessário que ocorra uma realização, em âmbito municipal, de um diagnóstico sobre a sua geração, identificando o volume total gerado e as suas principais características e propriedades.

Neste aspecto, escolheu-se para o estudo a cidade de Pau dos Ferros/RN, localizada na região do semiárido, no interior do estado do Rio Grande do Norte. Essa escolha se dá pela importância que a cidade representa para o interior do estado, devido à ampla região de influência, que segundo Dantas e Clementino (2013), ultrapassam a microrregião, se estendendo também para outros estados. Esta cidade é de certa forma beneficiada pela concentração de fluxo de população, mercadorias e dinheiro, que circunda os estados do Rio Grande do Norte, Ceará e Paraíba (DANTAS E CLEMENTINO, 2013).

Com o desenvolvimento do município de Pau dos Ferros, ocorreu o crescimento da quantidade de construções e consequentemente da geração de resíduos de construção civil (RCC). Pela grande geração de RCCs na cidade de Pau dos Ferros e pelos impactos que estes consumos acarretam ao meio ambiente será possível ainda, promover uma divulgação técnica referente ao assunto para a cadeia produtiva da construção civil na região.

A gestão dos resíduos sólidos em um município é um grande desafio, principalmente quando se trata de resíduos de construção civil. Diante disso, este trabalho tem como objetivo principal fazer um diagnóstico da geração de Resíduos de Construção Civil (RCC) na cidade de Pau dos Ferros/RN.

\section{Revisão de Literatura}

\subsection{Resíduos de Construção Civil: Conceito, classificação e destinação}

A Lei 12.305/10 que estabelece a Política Nacional de Resíduos Sólidos de acordo com o Ministério do Meio Ambiente, Brasil (2010) define no artigo 13, resíduo da construção e demolição como sendo os gerados das construções, reformas, reparos e demolições de obras de construção civil incluindo os resultantes da preparação e escavação de terrenos para obras civis.

Para Pinto (1999), os Resíduos de Construção Civil (RCC) são resíduos gerados a partir da extração da matéria natural utilizado nas obras civis, como materiais de construção e de reforma, até o final da obra. O autor ainda afirma que esse tipo de resíduo acaba despercebido 
pela população, devido não gerar nenhum tipo de odor como os resíduos sólidos provenientes do lixão, porém esse resíduo pode provocar a proliferação de vetores, o entupimento de tubulações, a contaminação dos solos e a poluição visual.

O CONAMA, através da Resolução no 307, de 5 de julho de 2002, estabelece que:

\begin{abstract}
Os resíduos da construção civil são provenientes de construções, reformas, reparos e demolições de obras de construção civil, e os resultantes da preparação e da escavação de terrenos, tais como: tijolos, blocos cerâmicos, concreto em geral, solos, rochas, metais, resinas, colas, tintas, madeiras e compensados, forros, argamassa, gesso, telhas, pavimento asfáltico, vidros, plásticos, tubulações, fiação elétrica etc., comumente chamados de entulho de obras, caliça ou metralha (CONAMA, 2002).
\end{abstract}

A classificação destes resíduos é determinada pelo Conselho Nacional do Meio Ambiente (CONAMA) através da Resolução no 307, de 5 de julho de 2002, alterada pelas Resoluções 348, de 2004, no 431, de 2011, e no 448/2012, em seu artigo $3^{\circ}$, como apresentado na tabela 1.

Em relação ao destino final, segundo o SINDUSCON-SP (2012), as deposições irregulares são comuns nos municípios brasileiros, porém provocam desperdício de materiais e custos elevados para as ações corretivas diante da falta de alternativas para destinação ou disposição correta.

Essas deposições irregulares acarretam impactos sanitários e ambientais relacionados aos resíduos de construção civil (RCC), os quais comprometem a paisagem urbana e o tráfego de veículos e de pedestres, além de contribuir significativamente com os problemas de drenagem urbana ao acumular resíduos tornam-se um meio favorável à presença de vetores, afetando, portanto, a saúde pública dos municípios.

Tabela 1 - Classificação e definição dos RCC (CONAMA - Resolução no 307)

\begin{tabular}{|c|c|}
\hline Classificação & Definição \\
\hline Classe A & $\begin{array}{l}\text { são os resíduos reutilizáveis ou recicláveis como agregados, tais como: a) } \\
\text { de construção, demolição, reformas e reparos de pavimentação e de outras } \\
\text { obras de infra-estrutura, inclusive solos provenientes de terraplanagem; b) } \\
\text { de construção, demolição, reformas e reparos de edificações: componentes } \\
\text { cerâmicos (tijolos, blocos, telhas, placas de revestimento etc.), argamassa e } \\
\text { concreto; c) de processo de fabricação e/ou demolição de peças pré- } \\
\text { moldadas em concreto (blocos, tubos, meios-fios etc.) produzidas nos } \\
\text { canteiros de obras. }\end{array}$ \\
\hline Classe B & $\begin{array}{l}\text { são os resíduos recicláveis para outras destinações, tais como: plásticos, } \\
\text { papel/papelão, metais, vidros, madeiras e gesso; (redação dada pela } \\
\text { Resolução } n^{\circ} \text { 431/11). }\end{array}$ \\
\hline Classe C & $\begin{array}{l}\text { são os resíduos para os quais não foram desenvolvidas tecnologias ou } \\
\text { aplicações economicamente viáveis que permitam a sua reciclagem ou } \\
\text { recuperação; (redação dada pela Resolução } n^{\circ} 431 / 11 \text { ). }\end{array}$ \\
\hline Classe D & $\begin{array}{l}\text { são resíduos perigosos oriundos do processo de construção, tais como } \\
\text { tintas, solventes, óleos e outros ou aqueles contaminados ou prejudiciais a } \\
\text { saúde oriundos de demolições, reformas e reparos de clínicas radiológicas, } \\
\text { instalações industriais e outros bem como telhas e demais objetos e } \\
\text { materiais que contenham amianto ou outros produtos nocivos a saúde. } \\
\text { (redação dada pela resolução }{ }^{\circ} 348 / 04 \text { ). }\end{array}$ \\
\hline
\end{tabular}

O artigo $10^{\circ}$ da Resolução nº 307/02 do CONAMA, determina que após a triagem os resíduos da construção civil deverão ser destinados como apresentado na tabela 2. 
Tabela 2 - Destinação dos RCC (CONAMA - Resolução no 307)

\begin{tabular}{|c|c|}
\hline Classificação & Definição \\
\hline Classe A & $\begin{array}{l}\text { deverão ser reutilizados ou reciclados na forma de } \\
\text { agregados ou encaminhados a aterro de resíduos classe A } \\
\text { de preservação de material para usos futuros; (nova } \\
\text { redação dada pela Resolução 448/12). }\end{array}$ \\
\hline Classe B & $\begin{array}{l}\text { deverão ser reutilizados, reciclados ou encaminhados a } \\
\text { áreas de armazenamento temporário, sendo dispostos de } \\
\text { modo a permitir a sua utilização ou reciclagem futura. }\end{array}$ \\
\hline Classe C & $\begin{array}{l}\text { deverão ser armazenados, transportados e destinados em } \\
\text { conformidade com as normas técnicas específicas. }\end{array}$ \\
\hline Classe D & $\begin{array}{l}\text { deverão ser armazenados, transportados e destinados em } \\
\text { conformidade com as normas técnicas específicas. (nova } \\
\text { redação dada pela Resolução 448/12). }\end{array}$ \\
\hline
\end{tabular}

\subsection{A indústria da construção civil e seus impactos}

Segundo Souza et al. (2004), o interesse nos resíduos de construção civil é cada vez maior, pois discute de questões ambientais, visto que não aproveitar materiais, seja na forma de resíduo de construção civil ou de outra natureza, significa desperdiçar recursos naturais, o que insere a indústria da construção civil como um dos principais focos nos debates sobre a busca pelo desenvolvimento sustentável.

Segundo Rocha (2006), os resíduos produzidos pela indústria da construção civil sempre se comportam de acordo com a necessidade que têm as mais diversas atividades de produção, sendo inevitável sua geração. No entanto, os países que buscam o crescimento econômico devem estar dispostos a preservar a natureza, isto é, tentar solucionar o problema diminuindo, pelo menos, o índice de resíduos de construção civil gerados.

Morais (2006) ressalta que, devido ao RCC ser um resíduo gerado em grande quantidade, é necessário que haja grandes áreas para a deposição final, o que resulta num rápido esgotamento da capacidade dos aterros. Neste aspecto, as deposições irregulares trazem uma preocupação maior, pois desencadeiam uma série de graves impactos, causando grandes danos ao meio ambiente e à população.

De acordo com Araújo (2014), a geração de resíduos a partir de obras de construção, demolição e reformas, representa um grande problema, fazendo-se necessário a elaboração de um plano de gestão para o gerenciamento e o monitoramento dessas atividades.

Para Wakim ${ }^{1}$ (2007) apud Santos (2008a) é importante e necessário que a gestão pública de cada município passe a abordar mais sobre o problema do gerenciamento dos RCC. Soluções emergenciais ou corretivas, como o aterramento de áreas naturais, seguindo as normas da resolução de $\mathrm{n}^{\circ} 307$ do CONAMA, seria uma forma de minimizar esse problema.

\subsection{Geração dos RCC em municípios brasileiros}

De acordo com as fases da construção, Santos (2008b), verificou que a composição do RCC, dentre outros aspectos, costuma variar em função das características regionais, são em sua maioria compostos por sobras de argamassa, tijolo, concreto, cerâmica, gesso, madeira, metais etc.

\footnotetext{
1 Wakim - WAKIM, L. R. J.

<http://www.mp.sp.gov.br/pls/portal/url/ITEM/21AC79B65A17E701E040A8C02C014D86>. Acesso em: $4 / 10 / 2007$
} 
Na tabela 3 é possível identificar a composição dos RCC em alguns estados brasileiros sendo ainda possível observar um maior percentual de resíduos de concreto e argamassa no estado de São Paulo, seguidos por Salvador e Florianópolis. Essa variabilidade na composição dos RCC apresenta características diferenciadas para cada país, estado, cidades e municípios, justificando a heterogeneidade em sua composição. (CARNEIRO, 2005).

Tabela 3 - Composição do resíduo de construção em diversas cidades brasileiras

\begin{tabular}{ccccc}
\hline Material & $\begin{array}{c}\text { São } \\
\text { Paulo/SP(1) }\end{array}$ & $\begin{array}{c}\text { Ribeirão } \\
\text { Preto/SP }{ }^{(2)}\end{array}$ & Salvador/BA $^{(3)}$ & Florianópolis/SC (4) \\
\hline $\begin{array}{c}\text { Concreto e } \\
\text { argamassa }\end{array}$ & $33 \%$ & $59 \%$ & $53 \%$ & $37 \%$ \\
\hline Solo e Areia & $32 \%$ & - & $22 \%$ & $15 \%$ \\
\hline Cerâmica & $30 \%$ & $23 \%$ & $14 \%$ & $12 \%$ \\
\hline Rochas & - & $18 \%$ & $5 \%$ & - \\
\hline Outros & $5 \%$ & - & $6 \%$ & $36 \%$ \\
\hline
\end{tabular}

(1) Brito Filho (1999); (2) Zordan (1997); (3) Projeto entulho bom (2001); (4) Xavier et al. (2002). Fonte: Carneiro (2005), adaptado.

\section{Metodologia}

A pesquisa se deu em duas etapas. Na primeira etapa foi realizada uma visita em doze canteiros de obras em atividade na cidade de Pau dos Ferros/RN. A figura 1 apresenta a posição dos doze canteiros visitados neste estudo. O objetivo desta visita era estimar o volume dos RCC gerados no processo de execução de diversas obras na cidade. Para isso, foi utilizado o Princípio matemático de Cavalieri, através do qual foi possível fazer a estimativa de volume de RCC.

Os canteiros de obras em atividade visitados para este estudo foram escolhidos considerando a zona de expansão populacional e comercial da cidade. Dessa forma, a pesquisa foi realizada nos bairros: Centro, São Geraldo, Paraíso, Carvão e João XXIII. As obras foram identificadas pelas letras A-I, conforme observado na figura 1. Com relação ao tipo da obra, apresentavam fins residenciais $(42 \%)$, comerciais $(25 \%)$ e públicos $(33 \%)$. As informações levantadas nas duas etapas foram compiladas e analisadas para elaboração dos resultados e conclusões deste estudo.

Na segunda etapa deste estudo foi elaborado um questionário sobre a gestão dos Resíduos de Construção Civil. O questionário foi aplicado nos canteiros de obras visitados na primeira etapa. O objetivo deste questionário foi obter informações sobre os RCC observados, tais como: a natureza do resíduo (construção, reforma ou demolição), etapa na qual o resíduo foi gerado e a destinação deste. O questionário abordou as seguintes perguntas:
a) Tipo de obra
b) Causa da geração do RCC
c) Materiais presentes no RCC
d) Destinação final
e) Reutilização do resíduo 


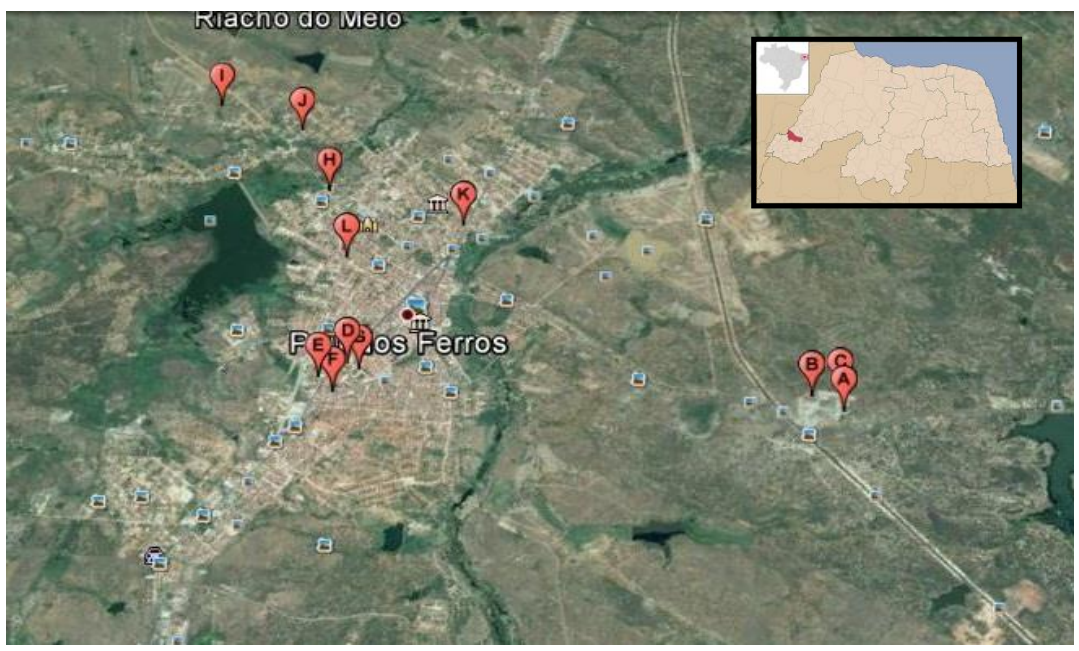

Figura 1 - Posição das obras visitadas neste estudo. Fonte: Google Earth, adaptado.

\section{Resultados e discussões}

A partir das visitas realizadas, foi observado que em 50\% das obras visitadas a área a ser construída é de $180 \mathrm{~m}^{2}$ ou mais. Essa informação do valor da área construída é relevante porque a dimensão da obra pode fornecer indícios da quantidade consumida de recursos naturais e da quantidade de resíduos descartados no canteiro. Neste sentido, ao final das construções, as obras de $180 \mathrm{~m}^{2}$ ou mais de área construída são as que geram mais RCC.

\subsection{Geração do Resíduo de Construção Civil}

Através da análise de procedimentos e da realização do questionário foi possível conhecer as principais fontes geradoras de RCC na cidade de Pau dos Ferros/RN.

De acordo com Medeiros (2002), os resíduos gerados diretamente pelas atividades de construção e demolição correspondem a, aproximadamente, $60 \%$ do total de resíduos sólidos urbanos gerados. Para com Pinto (1999), o resíduo gerado pela construção civil corresponde, em média, a 50\% do material que entra na obra.

Na figura 2 pode-se observar a principal causa de geração de resíduos comparando-se com a quantidade de canteiros de obra. É possível perceber que em $67 \%$ das obras visitadas a geração de RCC é oriunda de novas construções, $25 \%$ devido a reformas e $8 \%$ oriundo de demolições. Em nenhumas das obras visitadas ocorreu geração de RCC devido a erros de execução, de projeto ou de mudanças no projeto.

Na construção de uma nova edificação a falta de conhecimento e em muitos casos de aceitação de um novo material, resultam na falta de reutilização dos resíduos de construção civil e ainda na retirada de recursos naturais e principalmente na geração de mais RCC.

Para Karpinsk et al. (2009), nas obras de reforma há grande desperdício de RCC devido a ausência de cultura na reciclagem e reutilização, e a falta de conhecimento da potencialidade do resíduo como material de construção pela área técnica do setor da construção civil são as causas principais da geração de resíduos nessa etapa. E assim materiais incorporados na edificação tanto em construções novas como em reformas, na opinião de Karpinsk et al. (2009), irão gerar mais resíduos ao longo dos anos, pois é necessário a manutenção das edificações, o que pode provocar a redução da vida útil ou do desempenho da edificação. 


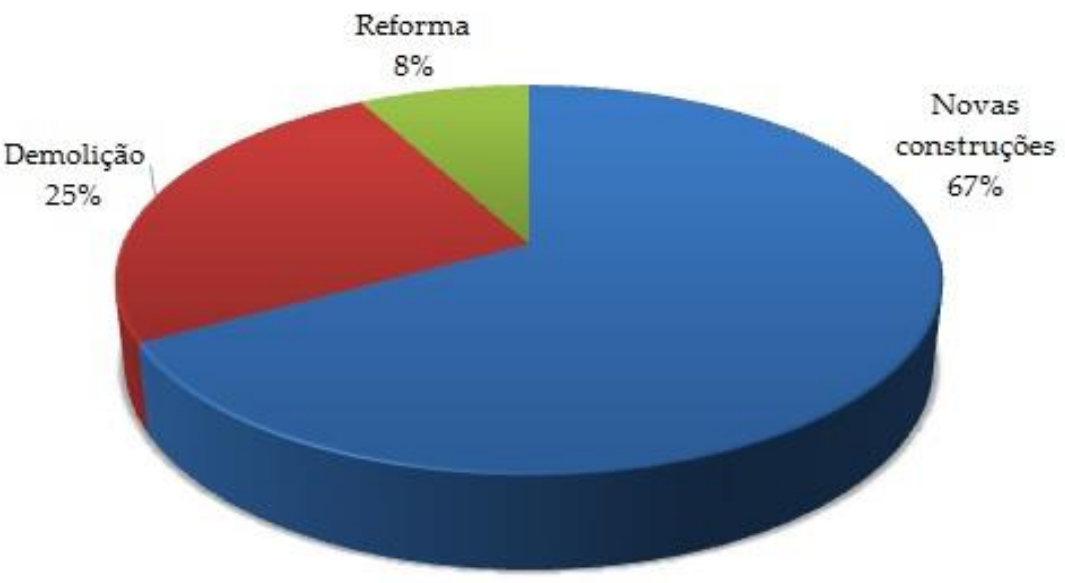

Figura 2 - Causas da geração do RCC em Pau dos Ferros Fonte: Elaborado pelos autores.

\subsection{Caracterização visual do RCC}

O resíduo de construção civil é diferente em cada região e pode ser constituído por material descartado ou inutilizável do canteiro de obra, isto é, tijolos, revestimento cerâmico, argamassa, concreto, tinta, latas de tinta, metais, gesso, plástico, papel e madeira. O tipo de material presente no RCC depende dos materiais empregados na construção e processos construtivos utilizados.

Na figura 3 é apresentado registro fotográfico de dois canteiros visitados. Na figura 3(a) é possível observar madeira, gesso, plásticos, argamassa e tijolos cerâmicos ao fundo. Na figura 3(b) observa-se concreto, material cerâmico, mas a maior parte do resíduo é constituída de argamassa. Na figura 3(c), o resíduo é constituído principalmente de tijolo cerâmicos, mas observa-se também a presença de argamassa. Já na figura 3(d) observa-se principalmente considerável volume de madeira presente no resíduo, provavelmente oriunda do emprego nas formas da obra. Portanto, a maior parte do resíduo é classificado de acordo com a Resolução 307/2002 do CONAMA na Classe A e podem ser reciclados ou reutilizados como agregados. Foram observados ainda, madeira, plásticos e gesso, os quais são resíduos classificados na Classe B, conforme a Resolução 307/2002 do CONAMA alterada pela Resolução no 431/11.

Conforme Karpinsk et al. (2009), a composição e quantidade de RCC produzida depende principalmente do desenvolvimento do setor da construção local, da qualidade da mão-de-obra, das técnicas construtivas empregadas e do controle de qualidade do processo produtivo, quando existe.

A figura 4 mostra a influência de cada etapa da obra, assim é possível saber a composição do resíduo de construção civil. É possível observar que a maior parte dos RCC gerados são oriundos de revestimento (figura 3(b)), em seguida a maior etapa que gera resíduos é a etapa de alvenaria, resíduos observados principalmente na figura 3(c), na sequência a etapa de concretagem (figura 3(d), devido a utilização de formas) e seguida pela de acabamento.

Em relação à composição do RCC, Camargo² (1995) apud Karpinsk et al. (2009), afirma que, o entulho que sai do canteiro de obras é composto, basicamente, por $64 \%$ de argamassa, $30 \%$ de componentes de vedação, como tijolo maciço, tijolo furado e blocos de concreto, e $6 \%$ de outros materiais, como concreto, pedra, areia, metais e plásticos.

2 CAMArgO, A. Minas de entulho. Revista de Tecnologia da Construção - Tèchne, ano 3, no 15, p. 15-19, 1995. 

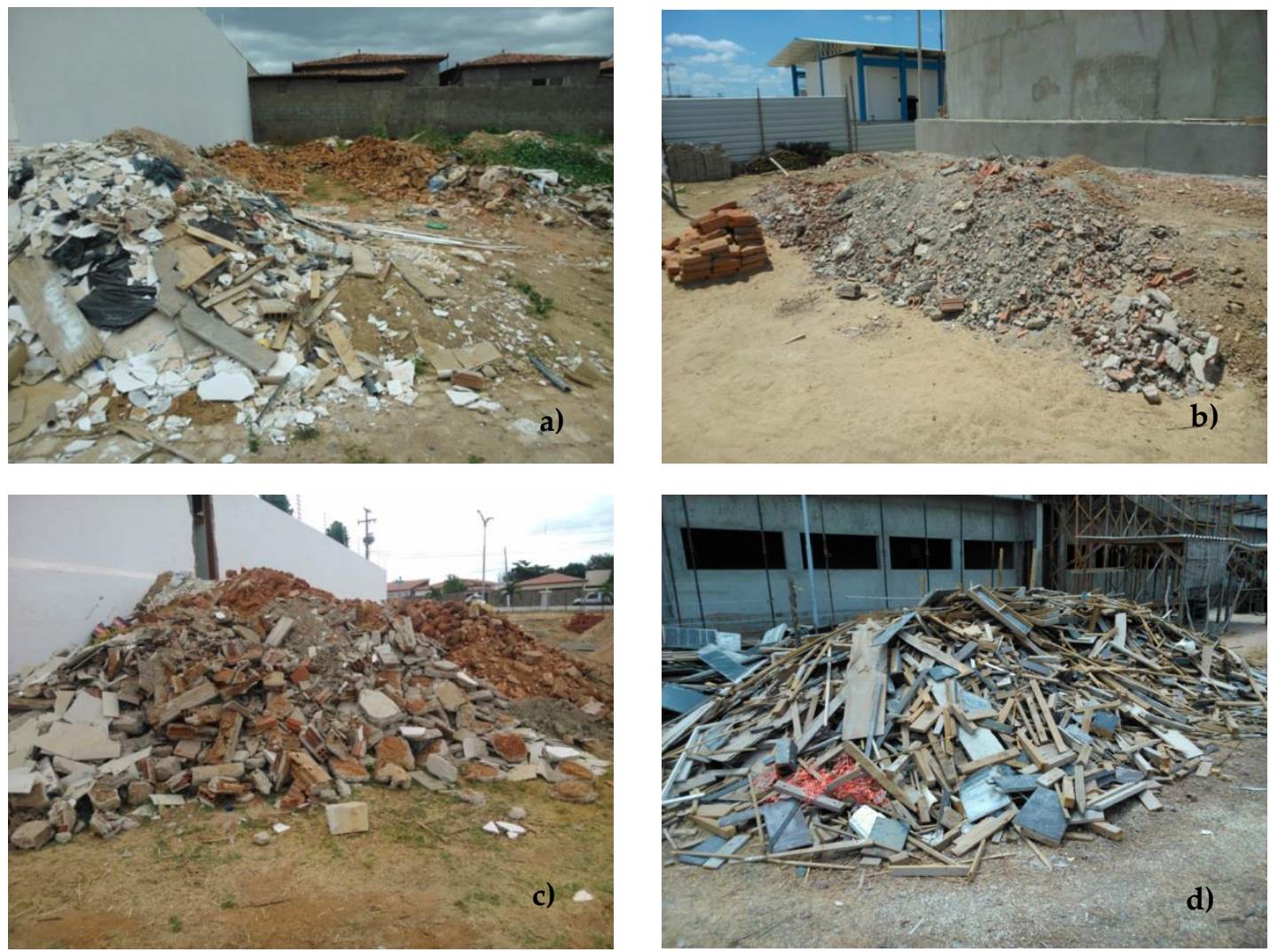

Figura 3 - Resíduo de construção civil em 4 canteiros diferentes.

Fonte: Elaborado pelos autores.

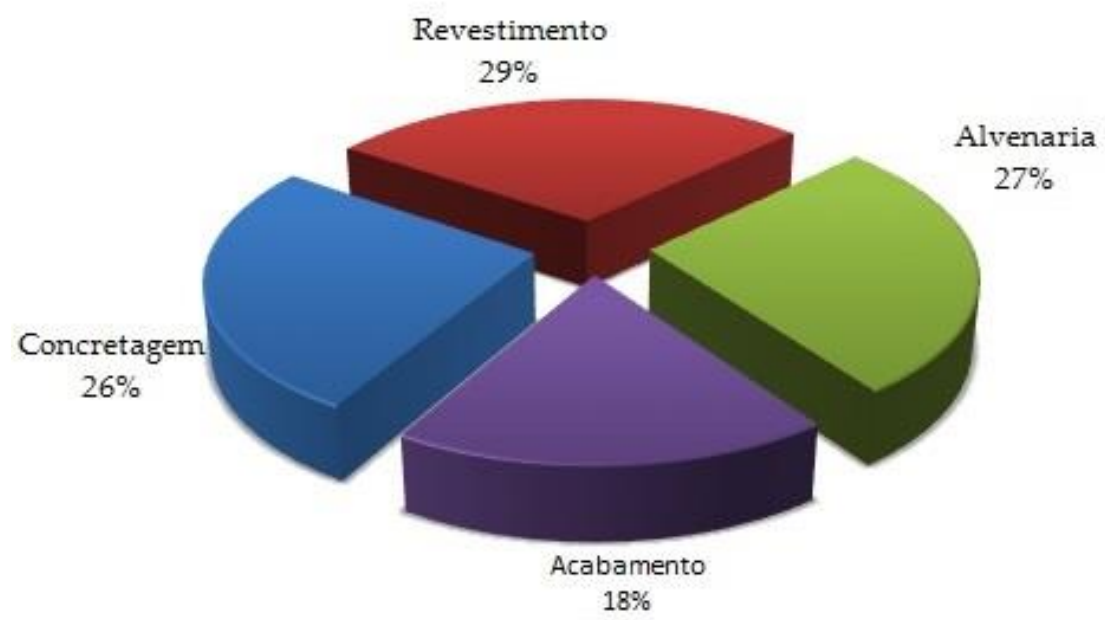

Figura 4 - Influência de cada etapa da obra na geração de RCC Fonte: Elaborado pelos autores.

\subsection{Volume de RCC gerado em Pau dos Ferros/RN}

A estimativa do volume do RCC gerado pela obra é necessária para retratar, através de números, a situação que o crescimento urbanístico e populacional acarreta através do desenvolvimento do setor 
da construção civil e a consequente geração de impactos ambientais. Segundo Bernardes et al. (2008), a identificação do volume total gerado é importante para o diagnóstico da geração de RCC e consequentemente para um bom gerenciamento desses resíduos.

A tabela 4 apresenta a estimativa de volume de cada obra visitada de acordo com a localização de cada canteiro. Analisando a tabela observa-se que mais de $180 \mathrm{~m}^{3}$ de volume de RCC foram gerados em apenas 12 canteiros de obras (dados obtidos apenas durante as visitas), logo o volume não se refere ao que foi gerado durante todo o decorrer da obra. Portanto, muito mais RCC foi gerado em todas as obras. Ainda na tabela é possível verificar que as obras com maior geração de resíduos são as obras B e C, pois são construções de maiores e, portanto, influenciam consideravelmente na quantidade de resíduos de construção civil gerado no município de Pau dos Ferros/RN.

Tabela 4 - Estimativa do volume de RCC por canteiro de obra realizado na cidade de Pau dos Ferros/RN

\begin{tabular}{|c|c|c|}
\hline Obra & Localização & Volume estimado $\left(\mathrm{m}^{3}\right)$ \\
\hline $\mathrm{A}$ & Bairro São Geraldo - BR 226 & 4,01 \\
\hline B & Bairro São Geraldo - BR 226 & 44,45 \\
\hline C & Bairro São Geraldo - BR 226 & 37,52 \\
\hline $\mathrm{D}$ & Centro - Av. Independência & 3,56 \\
\hline E & Centro - Av. Independência & 27,84 \\
\hline $\mathrm{F}$ & Centro - Rua São João & 4,98 \\
\hline G & Centro - Antônio F. de Oliveira & 6,27 \\
\hline $\mathrm{H}$ & Bairro Paraíso - Rua 13 de maio & 8,23 \\
\hline I & Bairro Carvão & 4,96 \\
\hline $\mathrm{J}$ & Bairro Carvão & 23,46 \\
\hline $\mathrm{K}$ & Bairro João XXIII - Av. Independência & 1,24 \\
\hline \multirow[t]{2}{*}{$\mathrm{L}$} & Bairro Paraíso - Rua Joaquim Torquato & 15,49 \\
\hline & Total de volume estimado & 182,01 \\
\hline
\end{tabular}

\subsection{Destinação final do RCC}

Da analise das informações coletadas no questionário verificou-se que o RCC é retirado da maioria das obras por veículos fretados pelos proprietários. Isso ocorre devido à demora do veículo municipal que passa nos locais das obras e a necessidade da sua retirada, pois o volume do RCC ocupa muito espaço nos canteiros de obra. Há obras que retiram os RCC com veículos próprios, ou ainda, abandonam os resíduos em terrenos baldios próximo ao canteiro de obra ou em canteiros da via pública.

Verificou-se que grande parte dos responsáveis das obras desconhecem o destino final dos resíduos. Isso se deve ao fato que as empresas coletoras/transportadoras não os informam e/ou os próprios responsáveis não demostram interesse a destinação do RCC. Das obras visitadas $67 \%$ sabiam a destinação do resíduo e 33\% relataram que o RCC é enviado para terrenos abandonados.

A Resolução 307/02 do CONAMA alterada pela Resolução 448/12 determina no artigo $10^{\circ}$ os resíduos de construção civil, após triagem deverão ser destinados de acordo com a classe. Para os resíduos observados nas obras dessa pesquisa, Classe A e B, a resolução determina que os resíduos Classe A deverão ser reutilizados ou reciclados na forma de agregados ou encaminhados a aterro de resíduos classe A que preservem o material para usos futuros. Já os resíduos Classe B, a resolução 
determina que deverão ser reutilizados, reciclados ou encaminhados para áreas de armazenamento temporário, devendo ser dispostos de modo que possam ser utilizados ou reciclados no futuro.

Dos canteiros de obra visitados apenas 1 reaproveitou os resíduos na obra, a reutilização foi como aterro. Da análise do questionário verificou-se que não há nenhuma orientação dos órgãos públicos aos responsáveis pelos canteiros de obra sobre a correta utilização do RCC. A orientação é fundamental para a diminuição do impacto ambiental causado pela indústria da construção civil. Conforme Kulatunga et al. (2006), a reciclagem de RCC é de suma importância, pois reduz o impacto ambiental, prevenindo um aumento da área necessária da disposição final de resíduos e também evitando a exploração de matérias-primas não renováveis.

\section{Conclusões}

Neste trabalho, foi realizado um diagnóstico da situação do RCC de algumas obras da cidade de Pau dos Ferros/RN.

Foi observado que maior porcentagem de RCC é oriunda de construção, demolição e reforma. Da analise do questionário foi verificado que a etapa que mais contribui para a geração de RCC é a de revestimento. Do resultado das medições realizadas no RCC presente nas obras durante as visitas, obteve-se uma estimativa de $180 \mathrm{~m}^{3}$ de volume total gerado.

A partir do questionário, verificou-se que grande parte dos responsáveis pelas obras desconhecem o destino final dos resíduos. A maioria dos canteiros, nos quais a pesquisa foi realizada, produz um RCC que pode ser reutilizável/reciclável. Porém, pela falta de conhecimento o resíduo não era reutilizado nem reciclado e apenas rejeitado. A composição do resíduo de construção civil (RCC) está condicionada aos processos construtivos utilizados, portanto depende da região geradora.

Os RCC observados nos canteiros foram classificados na Classe A e B na Resolução 307/2002 do CONAMA, portanto podem ser reutilizados ou reciclados. A adoção dessa medida estaria contribuindo para a economia de energia para produção de novos materiais e para a preservação do meio ambiente, pois evitaria a retirada de recursos naturais. Além disso, salienta-se que a deposição inadequada dos RCC influencia no aparecimento de problema sanitários nas cidades, como a proliferação de vetores, causando problemas a saúde pública.

Observa-se o descumprimento dos canteiros de obra à Resolução no 307/02 do CONAMA em relação a disposição dos resíduos e a destinação final. Portanto, na cidade de Pau dos Ferros/ RN há a necessidade de políticas públicas, elaboradas pelo próprio município em prol do meio ambiente para melhorar a gestão dos resíduos de construção civil, reduzindo a geração de RCC e orientando e proporcionando soluções adequadas para o destino dos resíduos oriundos da construção civil.

\section{Referências}

BARBISAN, A.O.; WERGENES, T.N.; TURELLA, E.C.L.; NORA, D.D.; SPADOTTO, A. Impactos ambientais causados pela construção civil. Unoesc \& Ciência - ACSA. 2012;2(2):173-180. ISSN 21783446.

BERNARDES, A.; THOMÉ, A.; PRIETTO, P. D. M.; ABREU, A. G.. Quantificação e classificação dos resíduos da construção e demolição coletados no município de Passo Fundo, RS. Ambiente Construído, Porto Alegre. 2008;8(3):65-76.

Ministério do Meio Ambiente. Lei № 12.305, de 2 de Agosto de 2010. Institui a Política Nacional de Resíduos Sólidos; altera a Lei no 9.605, de 12 de fevereiro de 1998; e dá outras providências. Brasil, 2010. Disponível em: <http://www.planalto.gov.br/ccivil_03/_ato2007-2010/2010/lei/112305.htm>. Acesso em: 22 fev. 2015. 
Ministério do Meio Ambiente; Conselho Nacional de Meio Ambiente. Resolução 307, de 5 de julho de 2002 - Estabelece diretrizes, critérios e procedimentos para a gestão dos resíduos da construção civil. Brasília (Brasil): Ministério do Meio Ambiente; 2002. Disponível em: $<$ http://www.mma.gov.br/port/conama/legiabre.cfm?codlegi=307>. Acesso em: 22 fev. 2015.

Resolução CONAMA no 348, de 16 de agosto de 2004. Altera a Resolução no 307/02 (altera o inciso IV do art. 3o). Brasília (Brasil): Ministério do Meio Ambiente; 2004. Disponível em: $<$ http://www.mma.gov.br/port/conama/legiabre.cfm?codlegi=449>Acesso em: 22 out. 2015.

Resolução CONAMA nº 431, de 24 de maio de 2011. Altera o art. 3oda Resolução no 307/2002. Brasília (Brasil): Ministério do Meio Ambiente; 2011. Disponível em: $<$ http://www.mma.gov.br/port/conama/legiabre.cfm?codlegi=649>Acesso em: 22 out. 2015.

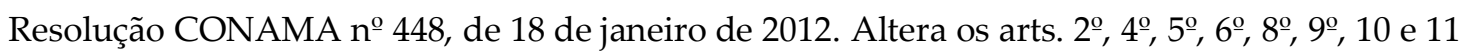
da Resolução no 307, de 5 de julho de 2002, do Conselho Nacional do Meio Ambiente - CONAMA. Brasília (Brasil): Ministério do Meio Ambiente; 2012. Disponível em: $<$ http://www.mma.gov.br/port/conama/legiabre.cfm?codlegi=672>. Acesso em: 22 fev. 2015.

CARNEIRO, F. P. Diagnóstico e ações da atual situação dos Resíduos de construção e demolição na cidade do Recife [dissertação]. João Pessoa/PB: Universidade Federal da Paraíba/UFPB; 2005. 124p.

DANTAS, J.R.Q.; CLEMENTINO, M.L.M. As cidades (inter) médias no desenvolvimento regional: um estudo sobre Pau dos Ferros (RN). Anais: Encontros Nacionais da ANPUR; 2013; Recife, Brasil. Disponível em:

$<$ http://unuhospedagem.com.br/revista/rbeur/index.php/anais/article/view/4340/4210>. Acesso em: 24 out. 2015.

KARPINSK, L. A.; PANDOLFO, A.; REINEHR, R.; KUREK, J.; PANDOLFO, L.; GUIMARÃES, J. Gestão Diferenciada de Resíduos da Construção Civil: Uma Abordagem Ambiental. Porto Alegre: Edipucrs; 2009. 163 p.

KULATUNGA U., AMARATUNGA D., HAIGH R. and RAMEEZDEEN R. ( 2006 ). Attitudes and perceptions of construction workforce on construction waste in Sri Lanka. Management of Environmental Quality: An International Journal, 2006;17(1):57-72 .

MORAIS, G.M.D. Diagnóstico da deposição clandestina de resíduos de construção e demolição em bairros periféricos em Uberlândia: Subsídios para uma gestão sustentável [Dissertação]. Uberlândia: Faculdade de Engenharia Civil/UFU; 2006. 134p..

NATIONAL RESEARCH CONUNCIL. Materials count: the case for material flows analysis. Wshington D. C.: National Academies Press, 2004.

PINTO, T. P. Metodologia para a gestão diferenciada de resíduos sólidos da construção urbana [Tese]. São Paulo: Escola Politécnica/USP; 1999. 189 p.

ROCHA, E.G.A. Os resíduos sólidos de construção e demolição: gerenciamento, quantificação e caracterização. Um estudo de caso no Distrito Federal [Tese]. Brasília: Departamento de Engenharia Civil e Ambiental/UnB; 2006. 155p. 
SANTOS, A. N. Diagnóstico da situação dos resíduos de Construção e Demolição (RCD) no Município de Petrolina (PE) [Dissertação]. Recife: Programa de Pós-Graduação em Engenharia Civil/UNICAP; 2008a. 111p.

SANTOS, L. C. dos. A questão do lixo urbano e a geografia. In: $1^{\circ}$ Simpósio de Pós-Graduação em Geografia do Estado de São Paulo; 2008 nov. 11-19; SÃO PAULO.

SINDUSCON-SP. Resíduos da construção civil e o estado de São Paulo. Sindicato da indústria da construção civil do estado de São Paulo. 2012. 85 p.

SOUZA, U.E.L.; PALIARI, J. C.; AGOPYAN, V.; ANDRADE, A. C. Diagnóstico e combate à geração de resíduos na produção de obras de construção de edifícios: uma abordagem progressiva. Ambient. Constr. 2004;4(4):33-46. 